\title{
The Role of Modified Expansion Sphincter Pharyngoplasty in Multilevel Obstructive Sleep Apnea Syndrome Surgery
}

\author{
Francesco Lorusso $^{1}$ Francesco Dispenza $^{1}$ Domenico Michele Modica ${ }^{1}$ Salvatore Gallina ${ }^{1}$ \\ ${ }^{1}$ Department of Otolaryngology, Policlinico Universitario Paolo \\ Giaccone, Palermo, Italy \\ Address for correspondence Francesco Lorusso, MD, Department of \\ Otolaryngology, Policlinico Universitario Paolo Giaccone, via del \\ Vespro 129, Palermo 90100, Italy \\ Int Arch Otorhinolaryngol 2018;22:432-436. \\ (e-mail: dott.francescolorusso@gmail.com).
}

\begin{abstract}
Introduction Obstructive sleep apnea syndrome (OSAS) is a sleep disorder caused by an excessive narrowing of the pharyngeal airway that also collapses during inspiration, with an important role played by the lateral pharyngeal wall in the development of the obstruction.

Objective To describe our surgical experience with modified expansion sphincter pharyngoplasty (MESP) in the management of lateral collapse in upper airway multilevel surgery.

Methods A total of 20 patients with moderate to severe OSAS were recruited in the Ear, Nose and Throat (ENT) Department of the University of Palermo, Italy. All of the

\section{Keywords}

- obstructive sleep apnea syndrome

- soft palate

- obstructive sleep apnea hypopnea syndrome

- sleep-disordered breathing

- nasopharyngeal diseases

- sleep apnea syndromes enrolled patients refused the ventilatory therapy. The subjects were evaluated for snoring, and daytime sleepiness had a clinical evaluation including collection of anthropometric data and ENT examination and rhinofibroscopy with Müller maneuver. The patients undergoing upper airway multilevel surgery and we selected for MESP the patients with an oropharyngeal transverse pattern of collapse at Müller maneuver.

Results In the postoperative assessment, all of the patients reported a reduction in snoring scores and daytime sleepiness. We observed a reduction in the mean apneahypopnea index $(\mathrm{AHI})$ of $57.5 \%$ of the sample, which decreased from a mean value of 41.7 ( \pm 21.5$)$ to $17.4( \pm 8.9)(p<0.05)$, with a success rate, according to the Sher criteria, of $65 \%$. We observed very few postoperative complications.

Conclusion Modified expansion sphincter pharyngoplasty in multilevel surgical therapy preceded by a careful selection of patients has proven to be effective in treating patients with moderate to severe syndromes.
\end{abstract}

\section{Introduction}

Obstructive sleep apnea syndrome (OSAS) is a sleep disorder caused by an excessive narrowing of the pharyngeal airway that collapses during inspiration, resulting in increased negative intrathoracic pressure, which in turn exacerbates the condition. ${ }^{1}$ The consequence of the collapse of the upper airway is the reduction of blood oxygenation; for this reason,
OSAS is considered a systemic disease, and over the last decades, attention to persistent snoring, particularly when associated with apnea syndrome, has hugely increased. ${ }^{2}$ These obstructive respiratory events are typically associated with cortical arousals and microdesaturation, which entail a fragmentation of sleep and an increase in the activity of the sympathetic nervous system. ${ }^{3}$ The prevalence of the disease is settled at $\sim 3-7 \%$, and there are many factors that makes received

December 6, 2017

accepted

March 18, 2018

published online

May 9, 2018
DOI https://doi.org/

10.1055/s-0038-1648248.

ISSN $1809-9777$.
Copyright $\odot 2018$ by Thieme Revinter

Publicações Ltda, Rio de Janeiro, Brazil
License terms

(c) $(1) \$$ 
people predisposed to develop this disorder, such as age, male gender, obesity, ${ }^{4}$ family history, menopausal and craniofacial abnormalities, and habits such as smoking cigarettes and abusing alcohol. ${ }^{5}$ It can be considered a multisystem disease because poor oxygenation of the body at night determines important repercussions on the whole organism. This disease also affects children, and in most of cases it is related to adenotonsillar hypertrophy. ${ }^{6}$ Several surgical techniques have been developed in recent years, including anterior palatoplasty, ${ }^{2}$ lateral pharyngoplasty, ${ }^{7}$ and expansion sphincter pharyngoplasty. ${ }^{8}$

The purpose of the present study is to describe our surgical experience on modified expansion sphincter pharyngoplasty (MESP) in upper airway multilevel surgery.

\section{Material and Methods}

A total of 20 patients with moderate to severe OSAS were recruited in our Ear Nose and Throat (ENT) Department between September 2012 and February 2015. The sample consisted of 19 men and 1 woman, with an average age of 50 years (mean: $25 \pm 8$ years). The selected patients had an mean apnea-hypopnea index (AHI) of $40.9 \pm 22.7$. All of the enrolled patients refused the ventilatory therapy with continuous positive airway pressure (CPAP). We excluded patients with macroglossia, craniofacial abnormalities, and body mass index (BMI) higher than 35 .

All of the patients underwent an anamnestic data collection, with a subjective assessment of the daytime sleepiness with the Epworth Sleepiness Scale (ESS), and a snoring assessment with a $0-10$ visual analogue scale (VAS; snoring: $0=$ no snoring; $10=$ maximum loudness of snoring) administered to their bed partners.

The patients underwent a clinical evaluation, which included the collection of anthropometric data (neck circumference, BMI), an ENT examination with rhinofibroscopy of the upper airway to grade the obstruction with Müller maneuver, using the grading proposed by Vicini. ${ }^{9}$ This grading consists of the evaluation of the collapse at the nasal level $(\mathrm{N})$, the oropharyngeal level $(\mathrm{O})$, and the hypopharyngeal level $(\mathrm{H})$. It is a quantitative evaluation of the collapse, in which 1 corresponds to lower than $25 \%$ of collapse; 2 , from 25 to $50 \%$; 3 , from 50 to $75 \%$; and 4 , more than $75 \%$ of collapse. And we also evaluated the dynamic pattern of the circular $(c)$, transverse $(t)$ and antero-posterior (a-p) collapses.

From this evaluation we selected for MESP the patients with an oropharyngeal transverse pattern of collapse.

These patients were subjected to an upper airway multilevel surgery. In our practice, this consists of nasal, oropharyngeal and hyoid suspension surgeries.

In our surgical practice, in patients with nasal diseases such as significant deviation of the nasal septum or polyposis, we preferred to anticipate the nasal surgery, followed by the oropharyngeal and hypopharyngeal surgeries two or three months later. In patients with relevant nasal obstruction we performed a multilevel surgery associating the nasal surgery, just in case of turbinate hypertrophy, with submucosal radiofrequency surgery without nasal packing, to prevent possible respiratory complications upon awakening, or immediate post-operative complications.

The oropharyngeal surgery consists of a tonsillectomy if the patients have not already been operated. The palatal surgery consists of an anterior palatoplasty ${ }^{2}$ and MESP. The latter, unlike the original surgical intervention described by Pang, ${ }^{8}$ does not enable the incision through the whole thickness of the palate, where a pocket is created, in which a portion of the palatopharyngeus muscle, which is not completely dissected, is fixed to the pterygoid hamulus. The hypopharyngeal surgery consists of a hyoid bone suspension. ${ }^{10}$

The follow-up was performed three months after the multilevel surgery.

For the descriptive statistics, the results were expressed as absolute and relative frequencies for the categorical variables, or as the mean \pm standard deviation (SD) for the continuous variables. A comparison of the quantitative variables between pre and postoperative was performed using the Student $t$-test. All tests were two-sided, and values of $p<0.05$ were considered statistically significant. The statistical analyses were performed using the Microsoft Excel 2003 (Microsoft Corporation, Redmond, WA, US) software and imported into the R-project ( $R$ Foundation for Statistical Computing, Vienna, Austria) software, version 2.15.2.

\section{Results}

All of the patients had a history of snoring associated with apnea, and, in most of cases, also with frequent arousal and sudden awakening. A total of 7 patients were undergoing pharmacological treatment for hypertension, 2 patients had major vessel atherosclerosis, and 2 other patients had a history of mild depressive anxiety disorder. In total, 3 patients were smokers, 3 were former smokers, and none normally drank alcohol. Respiratory allergies were reported by three patients.

Daytime sleepiness was evaluated with the ESS, and a pathologic score was achieved by 11 patients, with an average value of 10.4 .

After surgery (-Table $\mathbf{1}$ ), the postoperative assessment revealed in all patients a reduction in daytime sleepiness, with the persistence of a pathological score in three patients. The postoperative ESS mean score results were of 6.5 $(p<0,05)$.

The preoperative snoring score evaluated by a 10-point VAS was in average 9.2 ; postoperatively, the average of this score was reduced to $4.5(p<0.05)$.

From the collection of the anthropometric data, the mean BMI of the sample was of $28.6 \mathrm{~kg} / \mathrm{m}^{2}$ (mean: \pm 3.06 ); in 5 patients, it was between $30 \mathrm{~kg} / \mathrm{m}^{2}$ and $35 \mathrm{~kg} / \mathrm{m}^{2}$. In the postoperative evaluation, three months after the surgery, the BMI remained unchanged in all patients. The mean preoperative neck circumference was $41 \mathrm{~cm}$, and it remained unchanged in the postoperative evaluation.

Upon the oropharyngeal examination, 1 patient had been previously tonsillectomized, having, for that reason, tonsillar grade $0 ; 11$ patients had grade I; 6 had grade II; and 2 had grade III. No patient had tonsillar grade IV. All of the patients 
Table 1 Surgical procedures: modified expansion sphincter pharyngoplasty, tonsillectomy, turbinate surgery, anterior pharyngoplasty, hyoid suspension

\begin{tabular}{|l|l|l|l|l|l|}
\hline Patient & Surgical procedure & Preop AHI & Postop AHI & Reduction (\%) & Success of Sher criteria \\
\hline $\mathrm{I}$ & MESP-T & 37.9 & 19.3 & 49.1 & YES \\
\hline $\mathrm{II}$ & MESP-TONS-T & 79 & 20 & 74.7 & YES \\
\hline $\mathrm{III}$ & MESP-TONS-T & 18 & 9 & 50 & YES \\
\hline $\mathrm{IV}$ & MESP-TONS & 17 & 8.5 & 50 & YES \\
\hline $\mathrm{V}$ & MESP-T & 31.7 & 29.6 & 6.6 & NO \\
\hline $\mathrm{VI}$ & MESP-TONS-T & 19.7 & 7.6 & 61.6 & YES \\
\hline $\mathrm{VII}$ & MESP-TONS-T & 55.8 & 26 & 53.4 & NO \\
\hline VIII & MESP-TONS-T & 27 & 13 & 51.8 & NO \\
\hline $\mathrm{IX}$ & MESP-TONS & 30.8 & 15 & 51.3 & YES \\
\hline $\mathrm{X}$ & MESP-TONS-T & 70 & 25 & 64.3 & NO \\
\hline $\mathrm{XI}$ & MESP-TONS & 16 & 5 & 68.7 & YES \\
\hline $\mathrm{XII}$ & MESP-TONS-T-H & 73 & 30 & 58.9 & NO \\
\hline $\mathrm{XIII}$ & MESP-TONS & 33 & 3.5 & 89.4 & YES \\
\hline $\mathrm{XIV}$ & MESP-TONS-T-H & 58 & 19 & 67.2 & YES \\
\hline $\mathrm{XV}$ & MESP-T-H & 30 & 13 & 56.6 & YES \\
\hline $\mathrm{XVI}$ & MESP-ANT- TONS-T-H & 28.4 & 10 & 64.8 & YES \\
\hline $\mathrm{XVII}$ & MESP-TONS-T- H & 64 & 30 & 53.1 & NO \\
\hline $\mathrm{XVIII}$ & MESP-TONS-H & 30 & 12 & 60 & YES \\
\hline $\mathrm{XIX}$ & MESP-ANT-TONS-T-H & 38 & 16 & 57.9 & YES \\
\hline $\mathrm{XX}$ & MESP-ANT-TONS-T-H & 78 & 30 & 61.5 & YES \\
\hline & TOTAL & $41.7( \pm 21.5)$ & $17.4( \pm 8.9)$ & $57.5 \%$ & $65 \%$ \\
\hline
\end{tabular}

Abbreviations: AHI, apnea-hypopnea index; ANT, anterior pharyngoplasty; MESP, modified expansion sphincter pharyngoplasty; $\mathrm{H}$, hyoid suspension; postop, postoperative; preop, preoperative; T, turbinate surgery; TONS, tonsillectomy.

had prolapse of the soft palate, with hypertrophy of the uvula and posterior palatine pillars. A total of 13 patients had hypertrophy of the lower turbinates, 8 patients had nonstenosing nasal septum deviation, and 3 patients had been previously subjected to septal defect correction surgery. Three patients had nasopharyngeal hypertrophic lymphoid tissue.

Upon dynamic endoscopy with Müller maneuver in the pre- and postoperative evaluations, we observed (-Table 2) a reduction in nasal obstruction, decreasing from a mean value of 2.2 to a mean value of $1.85(p<0.05)$. Oropharyngeal obstruction was predominantly transverse in all patients according to the selection criteria, and it decreased postoperatively from a mean value of 3.15 to $1.2(p<0.05)$. Regarding the hypopharyngeal obstruction, we observed a preoperative reduction from a mean value of 1.7 to 1 $(p<0.05)$ ( - Fig. 1). From the pre- and postoperative polysomnographic evaluations, we obtained the results described in - Table 1 by evaluating the success rates according to Scher criteria (AHI reduction $>50 \%$ and $<20 \%$ ). ${ }^{11}$ We highlighted a reduction in the mean AHI of $57.5 \%$, which decreased postoperatively from a mean value of $41.7( \pm 21.5)$ to 17.4 ( $\pm 8.9 ; p<0.05$ ), with a success rate according to the Sher criteria of $65 \%$.
With this multilevel approach, we found an acceptable postoperative pain treated with paracetamol $1 \mathrm{~g}$ every 8 hours for the first 3 postoperative days, and then administered on request the following days. After the fifth postoperative day, none of the patients reported any need for analgesic therapy. We reported few postoperative complications: in two cases, an early hemorrhage occurred in the first postoperative day, and no case of fluid reflux from the nose was reported. In two cases, the patients presented a feeling of a persistent foreign body in the pharynx for a few months after the intervention; however, this was spontaneously resolved. In eight patients without a significant AHI reduction, we proposed an orthodontic treatment with a mandibular advancing device (MAD), obtaining further improvement in the OSAS.

\section{Discussion}

A multilevel procedure for the surgical therapy of OSAS was presented for the first time in 1989 by Waite and colleagues. $^{12}$ Fujita $^{13}$ was the first who discriminated between retropalatal and retrolingual obstructions, and, based on his insights, Riley et $\mathrm{al}^{14}$ developed the concept of multilevel surgery. 
Table 2 Müller maneuver in the pre-and postoperative assessments

\begin{tabular}{|c|c|c|}
\hline Patient & Preop Müller & Postop Müller \\
\hline $\mathrm{I}$ & $\mathrm{N}_{2} \mathrm{O}_{3 \mathrm{~T}} \mathrm{H}_{2 \mathrm{~T}}$ & $\mathrm{~N}_{2} \mathrm{O}_{1 \mathrm{~T}} \mathrm{H}_{1 \mathrm{~T}}$ \\
\hline II & $\mathrm{N}_{3} \mathrm{O}_{4 \mathrm{~T}} \mathrm{H}_{2 \mathrm{~T}}$ & $\mathrm{~N}_{3} \mathrm{O}_{1 \mathrm{~T}} \mathrm{H}_{1 \mathrm{~T}}$ \\
\hline III & $\mathrm{N}_{2} \mathrm{O}_{4 \mathrm{~T}} \mathrm{H}_{3 \mathrm{~T}}$ & $\mathrm{~N}_{2} \mathrm{O}_{2 \mathrm{~T}} \mathrm{H}_{2 \mathrm{~T}}$ \\
\hline IV & $\mathrm{N}_{3} \mathrm{O}_{3 \mathrm{~T}} \mathrm{H}_{1 \mathrm{~T}}$ & $\mathrm{~N}_{3} \mathrm{O}_{1 \mathrm{~T}} \mathrm{H}_{1 \mathrm{~T}}$ \\
\hline $\mathrm{V}$ & $\mathrm{N}_{1} \mathrm{O}_{3 \mathrm{~T}} \mathrm{H}_{2 \mathrm{~T}}$ & $\mathrm{~N}_{1} \mathrm{O}_{2 \mathrm{~T}} \mathrm{H}_{1 \mathrm{~T}}$ \\
\hline $\mathrm{VI}$ & $\mathrm{N}_{3} \mathrm{O}_{3 \mathrm{~T}} \mathrm{H}_{1 \mathrm{AP}}$ & $\mathrm{N}_{3} \mathrm{O}_{1 \mathrm{~T}} \mathrm{H}_{1 \mathrm{~T}}$ \\
\hline VII & $\mathrm{N}_{2} \mathrm{O}_{3 \mathrm{~T}} \mathrm{H}_{1 \mathrm{~T}}$ & $\mathrm{~N}_{2} \mathrm{O}_{1 \mathrm{~T}} \mathrm{H}_{1 \mathrm{~T}}$ \\
\hline VIII & $\mathrm{N}_{3} \mathrm{O}_{3 \mathrm{~T}} \mathrm{H}_{0}$ & $\mathrm{~N}_{3} \mathrm{O}_{1 \mathrm{~T}} \mathrm{H}_{0}$ \\
\hline IX & $\mathrm{N}_{3} \mathrm{O}_{3 \mathrm{~T}} \mathrm{H}_{2 \mathrm{~T}}$ & $\mathrm{~N}_{3} \mathrm{O}_{1 \mathrm{~T}} \mathrm{H}_{2 \mathrm{~T}}$ \\
\hline$x$ & $\mathrm{~N}_{3} \mathrm{O}_{3 \mathrm{~T}} \mathrm{H}_{2 \mathrm{~T}}$ & $\mathrm{~N}_{3} \mathrm{O}_{1 \mathrm{~T}} \mathrm{H}_{1 \mathrm{~T}}$ \\
\hline$X I$ & $\mathrm{~N}_{3} \mathrm{O}_{3 \mathrm{~T}} \mathrm{H}_{1 \mathrm{~T}}$ & $\mathrm{~N}_{3} \mathrm{O}_{1 \mathrm{~T}} \mathrm{H}_{1 \mathrm{~T}}$ \\
\hline XII & $\mathrm{N}_{1} \mathrm{O}_{3 \mathrm{~T}} \mathrm{H}_{1 \mathrm{~T}}$ & $\mathrm{~N}_{1} \mathrm{O}_{1 \mathrm{~T}} \mathrm{H}_{1 \mathrm{~T}}$ \\
\hline XIII & $\mathrm{N}_{3} \mathrm{O}_{4 \mathrm{~T}} \mathrm{H}_{3 \mathrm{~T}}$ & $\mathrm{~N}_{1} \mathrm{O}_{1 \mathrm{~T}} \mathrm{H}_{1 \mathrm{~T}}$ \\
\hline XIV & $\mathrm{N}_{1} \mathrm{O}_{4 \mathrm{~T}} \mathrm{H}_{0}$ & $\mathrm{~N}_{0} \mathrm{O}_{1 \mathrm{~T}} \mathrm{H}_{0}$ \\
\hline $\mathrm{XV}$ & $\mathrm{N}_{3} \mathrm{O}_{4 \mathrm{~T}} \mathrm{H}_{1 \mathrm{~T}}$ & $\mathrm{~N}_{1} \mathrm{O}_{2 \mathrm{~T}} \mathrm{H}_{1 \mathrm{~T}}$ \\
\hline $\mathrm{XVI}$ & $\mathrm{N}_{2} \mathrm{O}_{4 \mathrm{~T}} \mathrm{H}_{3 \mathrm{~T}}$ & $\mathrm{~N}_{1} \mathrm{O}_{1 \mathrm{~T}} \mathrm{H}_{1 \mathrm{~T}}$ \\
\hline XVII & $\mathrm{N}_{3} \mathrm{O}_{4 \mathrm{~T}} \mathrm{H}_{3 \mathrm{~T}}$ & $\mathrm{~N}_{1} \mathrm{O}_{1 \mathrm{~T}} \mathrm{H}_{1 \mathrm{~T}}$ \\
\hline $\mathrm{XVII}$ & $\mathrm{N}_{3} \mathrm{O}_{4 \mathrm{~T}} \mathrm{H}_{3 \mathrm{~T}}$ & $\mathrm{~N}_{1} \mathrm{O}_{1 \mathrm{~T}} \mathrm{H}_{1 \mathrm{~T}}$ \\
\hline XIX & $\mathrm{N}_{2} \mathrm{O}_{4 \mathrm{~T}} \mathrm{H}_{2 \mathrm{~T}}$ & $\mathrm{~N}_{1} \mathrm{O}_{1 \mathrm{~T}} \mathrm{H}_{1 \mathrm{~T}}$ \\
\hline$x X$ & $\mathrm{~N}_{3} \mathrm{O}_{4 \mathrm{~T}} \mathrm{H}_{2 \mathrm{~T}}$ & $\mathrm{~N}_{2} \mathrm{O}_{1 \mathrm{~T}} \mathrm{H}_{1 \mathrm{~T}}$ \\
\hline
\end{tabular}

Abbreviations: AP, antero-posterior collapse; $\mathrm{H}$, hypopharynx; $\mathrm{N}$, nose; $\mathrm{O}$, oropharyx; $\mathrm{T}$, transverse collapse.

In 2003, Cahali $^{7}$ was the first to focus the attention on the lateral pharyngeal wall in the development of OSAS. The author proposed the lateral pharyngoplasty, which has as its main purpose the stiffening and enlargement of the lateral walls, unlike the uvulopalatopharyngoplasty, in which the surgical goal is purely acaric of the soft palate, which is shortened and stiffened, and the only intervention on the sidewall is related to the tonsillectomy. ${ }^{1}$ Cahali has shown that the obstruction linked to the sidewalls of the pharynx is the only risk factor, in addition to the BMI and neck circumference, which act independently in the determinism of OSAS. ${ }^{15}$ Even the expansion sphincter pharyngoplasty (ESP), which was developed by Pang and Woodson in 2007,8 is based on the assumption that the pharyngeal obstruction is mainly related to the collapse of the lateral wall. This technique is much more conservative and respectful of palatal anatomy than the previous approaches. Based on the site and pattern of obstruction, we selected the patients with oropharyngeal transverse collapse to treat with MESP, which is even more respectful of the anatomical structures than the original technique proposed by Pang.

Such a technique has proven to be effective if used in selected patients; it is quite safe, and the postoperative pain felt by the patients is comparable to the pain felt after a tonsillectomy. We did not find any significant complications, either short- or long-term, with the exception of two cases of postoperative bleeding, which is a frequent complication of tonsillectomy in adult patients. None of the patients presented postoperative reflux of fluids through the nose. This technique has also achieved excellent compliance in terms of postoperative functional recovery; the oral feeds resumed on the first postoperative day, with a liquid and semiliquid diet without postoperative dysphagia. In the postoperative endoscopic controls, following Müller Maneuver, we found a significant improvement in the transverse oropharyngeal collapse pattern. The mean AHI of all patients decreased by half compared with what is was preoperatively.

Overall, the quality of the sleep of the patients improved, despite the fact that there was no substantial change in polysomnographic parameters in one patient. Waking state and patient concentration skills were overall improved, as evidenced by the average postoperative ESS. Patient number V did not achieve a significant improvement in the AHI probably because of its poor selection because he/she exhibited important retrognathia and a depressive syndrome in pharmacological treatment. In patients numbers VII, X, XII, XVII and XX, the

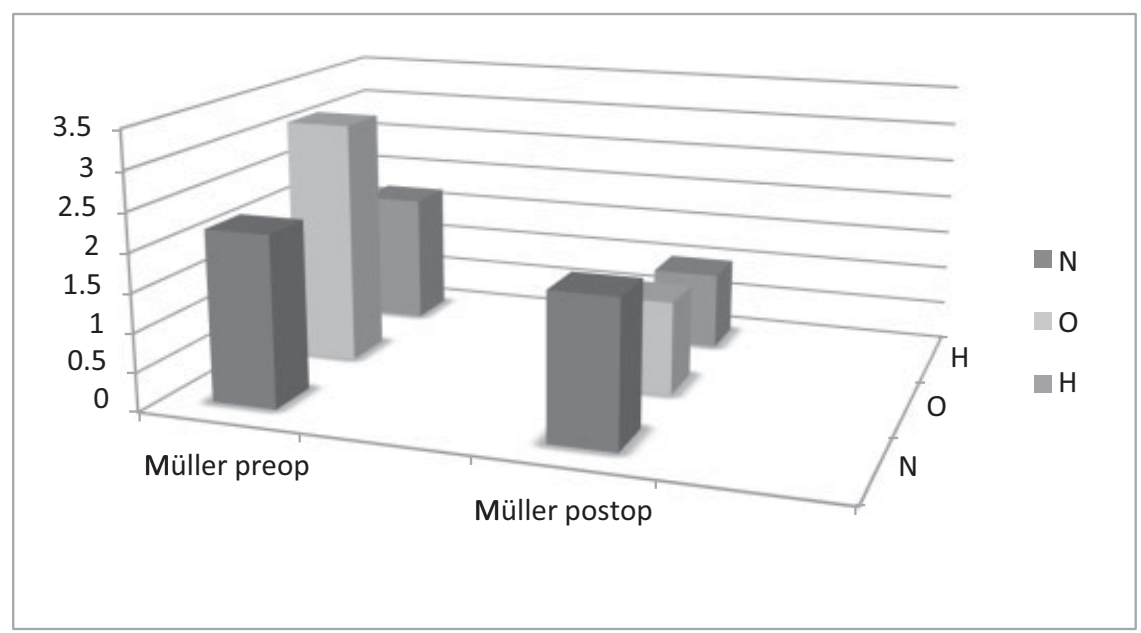

Fig. 1 Mean value of the collapse during Müller maneuver in the pre- and postoperative assessments. N: nose; O: oropharynx; H: hypopharynx; postop, postoperatively; preop, preoperatively. 
OSAS was extremely severe, but they were not compliant with the nasal continuous positive airway pressure (NCPAP) therapy; in these cases there was a reduction of $>50 \%$ in the $\mathrm{AHI}$, but it did not reach a value below $20 \%$, probably due to the high starting values.

\section{Conclusion}

Modified expansion sphincter pharyngoplasty in multilevel surgical therapy preceded by careful selection of patients has proven to be effective in treating patients with moderate to severe syndromes. Such results are even more encouraging if we refer in particular to the constant sensitive reduction in daytime sleepiness and the relatively low incidence of postoperative complications. However, the non-indifferent percentage of only partial improvements obtained in terms of postoperative AHI should not be neglected. Therefore, this therapy in our opinion cannot yet be considered completely reliable in every single case. It is, therefore, in our view, to be proposed, in cases of moderate to severe syndromes, in patients who are not compliant with the CPAP, or in patients with significant anatomical conformation that would presuppose a good surgical success according to the Friedman classification, ${ }^{16}$ in particular with hypertrophy of the palatine tonsils.

Lastly, the possibility in the case of partial surgical success to implement the treatment with mandibular advancement devices should be considered. ${ }^{17}$

Remembering postoperative CPAP, however, usually at lower pressures than before surgery, is still possible in failures, considering the substantial preservation of functional anatomy of the upper airway after the surgery we performed.

\section{References}

1 Gallina S, Dispenza F, Kulamarva G, Ballacchino A, Speciale R. Uvulopalatopharyngoplasty with tonsillectomy in the treatment of severe OSAS. B-ENT 2009;5(04):245-250

2 Pang KP, Tan R, Puraviappan P, Terris DJ. Anterior palatoplasty for the treatment of OSA: three-year results. Otolaryngol Head Neck Surg 2009;141(02):253-256
3 Caples SM, Gami AS, Somers VK. Obstructive sleep apnea. Ann Intern Med 2005;142(03):187-197

4 Lorusso F, Dispenza F, Saraniti C, Sireci F, Modica DM, Gallina S. Sleep disordered breathing: evaluation of dynamic patterns of the upper airways in obese subjects. Otorinolaringologia 2014; 64:57-64

5 Punjabi NM. The epidemiology of adult obstructive sleep apnea. Proc Am Thorac Soc 2008;5(02):136-143

6 Lorusso F, Gallina S, Modica DM, Di Salvo N, Riggio F. Bipolar Quantum Molecular Resonance versus Blunt Dissection tonsillectomy. B-ENT 2015;11(02):101-108

7 Cahali MB. Lateral pharyngoplasty: a new treatment for obstructive sleep apnea hypopnea syndrome. Laryngoscope 2003;113 (11):1961-1968

8 Pang KP, Woodson BT. Expansion sphincter pharyngoplasty: a new technique for the treatment of obstructive sleep apnea. Otolaryngol Head Neck Surg 2007;137(01):110-114

9 Vicini C, De Vito A, Benazzo M, et al. The nose oropharynx and larynx hypopharynx (Nohl) classification: a new system of standardized diagnostic examination for OSAHS patients. Eur Arch Otorhinolaryngol 2012;269(04):1297-1300

10 Riley RW, Powell NB, Guilleminault C. Obstructive sleep apnea and the hyoid: a revised surgical procedure. Otolaryngol Head Neck Surg 1994;111(06):717-721

11 Sher AE, Schechtman KB, Piccirillo JF. The efficacy of surgical modifications of the upper airway in adults with obstructive sleep apnea syndrome. Sleep 1996;19(02):156-177

12 Waite PD, Wooten V, Lachner J, Guyette RF. Maxillomandibular advancement surgery in 23 patients with obstructive sleep apnea syndrome. J Oral Maxillofac Surg 1989;47(12):1256-1261, discussion 1262

13 Fujita S. Obstructive sleep apnea syndrome: pathophysiology, upper airway evaluation and surgical treatment. Ear Nose Throat J 1993;72(01):67-72, 75-76

14 Riley RW, Powell NB, Guilleminault C. Obstructive sleep apnea syndrome: a review of 306 consecutively treated surgical patients. Otolaryngol Head Neck Surg 1993;108(02):117-125

15 Mesti JJ, Cahali MB. Evolution of swallowing in lateral pharyngoplasty with stylopharyngeal muscle preservation. Rev Bras Otorrinolaringol (Engl Ed) 2012;78(06):51-55

16 Friedman M, Salapatas AM, Bonzelaar LB. Updated Friedman Staging System for Obstructive Sleep Apnea. Adv Otorhinolaryngol 2017;80:41-48

17 de Britto Teixeira AO, Abi-Ramia LB, de Oliveira Almeida MA. Treatment of obstructive sleep apnea with oral appliances. Prog Orthod 2013;14:10 